\title{
María Victoria Porras en clave constructivista*
}

MARÍA VITORIA PORRAS ON CONSTUCTIVIST KEY

MARÍA VICTORIA PORRAS EM CHAVE CONSTRUSTIVISTA

\section{Martín Alonso Camargo Flórez** Andrés Leonardo Caballero Piza***}

Cuadernos de Música, Artes Visuales y Artes Escénicas

/ Volumen 11 - Número 2 / julio - diciembre de 2016

/ ISSN 1794-6670/ Bogotá, D.C., Colombia / pp. 159-171

Fecha de recepción: 8 de marzo de 2016

Fecha de aceptación: 17 de junio de 2016

Disponible en línea: 20 de febrero de 2017

doi:10.11144/Javeriana.mavae12-1.mvpc

* Este trabajo se ha realizado de forma independiente, sin ninguna vinculación a algún grupo de carácter institucional..

** Filósofo y magíster en Semiótica por la Universidad Industrial de Santander. Profesor de la Escuela de Artes Plásticas de la Universidad Industrial de Santander.

** Historiador y maestro en Bellas Artes por la Universidad Industrial de Santander.

Estudiante de Maestría en Artes, Cultura y Lenguajes de la Universidade Federal de Juiz de Fora (Minas Gerais, Brasil). 


\section{Resumen}

Este artículo busca tanto presentar un dosier de la carrera artística de la artista santandereana María Victoria Porras como cuestionar las interpretaciones que hiciera sobre su obra gráfica el historiador Germán Rubiano Caballero. A partir de un enfoque semiótico y de las nociones de extensiones prostéticas y significación simbólica, se intenta mostrar de qué modo las obras Ramajes del hombre, su hierro y Metales para una soledad plantean una crítica al desarrollismo colombiano, mas no una exaltación irreflexiva de este, como pretendía Rubiano, que las vincula con una forma particular de entender el arte politizado colombiano de la década de 1970. Unas obras que indagan sobre la responsabilidad de los seres humanos en la construcción de un futuro en el que la tecnología ha sido entendida como una extensión de la naturaleza en la lucha por la libertad, pero que, a falta de voluntad política, se trataría de un proceso suspendido y en espera de ser reactivado en el transcurso de la historia. Por último, el artículo plantea la necesidad de implementar un enfoque de investigación a partir de la historia social del arte que permita profundizar en el interés de la artista por trabajar el vínculo entre la naturaleza, la tecnología y la modernización, la relación de estos temas con las circunstancias históricas y culturales de su natal Barrancabermeja y el papel que desempeñó en su comprensión del arte el ambiente politizado de la Universidad Nacional de Colombia.

Palabras claves: arte santandereano; artes gráficas; Barrancabermeja, constructivismo.

\section{Abstract}

This article seeks both to present a dossier of the santanderean artist Maria Victoria Porras' career as to question the interpretations made on her graphic work by historian Germán Rubiano Caballero. From a semiotic approach and notions of "prosthetic extensions" and "symbolic significance", it attempts to show how The man's branches, his iron and Metals for solitude propose a criticism of the Colombian developmentalism and not a thoughtless exaltation of it, as was claimed by Rubiano, which links these artworks to a particular way of understanding the Colombian politicized art of the 1970s. Artworks that question the responsibility of human beings in building a future in which technology has been understood as an extension of nature in the struggle for freedom, but, in the absence of political will, it would be a suspended process waiting to be reactivated in the course of history. By last, this article points to the need for implementing a research approach from the social history of art in furtherance of the artist's interests to work on the link between nature, technology and modernization; the relationship of these issues with the historical and cultural circumstances of her native Barrancabermeja; and the role played by the politicized atmosphere of National University of Colombia in her understanding of art

Keywords: art of Santander; graphic arts;

Barrancabermeja; constructivism

\section{Resumo}

Este artigo procura apresentar um dossiê da trajetória artística da artista santandereana María Victoria Porras, como fazer questão nas interpretações que fizesse sobre sua obra gráfica o historiador Germán Rubiano Caballero. Partindo de um enfoque semiótico e das noções de "extensões prostética" y "significação simbólica", tenta-se mostrar do que modo as obras Ramajes del Hombre, su hierro e Metales para uma soledad planteiam uma crítica ao desenvolvimentismo colombiano, mas não uma exaltação irreflexiva de este, como pretendia Rubiano, quem as vincula como uma forma particular de entender a arte politizada colombiana da década de 1970. Umas obras que pesquisam sobre a responsabilidade dos seres humanos na construção de um futuro no que a tecnologia tem sido entendida como uma extensão da natureza na luta pela liberdade; mas que por falta de vontade política, se trataria de um processo suspendido e em espera a ser reativo no transcurso da história. Finalmente, o artigo planteia a necessidade de inserir um enfoque de pesquisa partindo da historia social da arte que permita aprofundar no interesse da artista por trabalhar o vinculo entre a natureza, a tecnologia e a modernização, a relação de estes temas com as circunstancias históricas e culturais de sua natal Barrancabermeja; e o pape que desempenhou em sua compreensão da arte no ambiente politizado da Universidade Nacional de Colombia.

Palavras chave: arte santandereana; artes gráficas

Barrancabermeja; construtivismo 


\section{INTRODUCCIÓN: DOSIER MÍNIMO}

Si tuviese que responderse a la pregunta de cuál fue la artista santandereana más representativa del arte a finales de la década de 1960 y comienzos de la de 1970 (bueno, bueno, está bien, después de Beatriz González), habría pocas dudas historiográficas de que el nombre por mencionar sería el de María Victoria Porras Giordanelli (1948). Los documentos encontrados no solo hablan en su favor, sino que facilitan su recuperación histórica a causa de la amplia circulación que tuvo su obra en algunos de los más renombrados proyectos y espacios expositivos de las artes gráficas de la época. Basta hurgar en los catálogos de la Exposición panamericana de artes gráficas: dibujo, grabado, diseño gráfico (1970), del Primer Salón de Artes Plástica de Acopex (1975), y de la 4 Bienal de Arte de Medellín: "Formar, informar, recrear" (1981), para comprobarlo. Sin embargo, y para evitarles la molestia, a continuación se presenta un dosier resumido de su trayectoria:

- Galería Colseguros (Bogotá, 1966)

- I Salón Joven de Artes Plásticas (Museo de Arte Contemporáneo, Bogotá, 1967)

- I Bienal de Grabado Latinoamericano y del Caribe (San Juan de Puerto Rico, 1970)

- Salón Panamericano de Artes Gráficas, en el X Festival de Arte de Cali (Cali, 1970)

- I Bienal Americana Artes Gráficas (Museo La Tertulia, Cali, 1971)

- Galería Belarca (Bogotá, 1972)

- $\quad$ III Bienal de Arte Coltejer (Medellín, 1972)

- III Bienal Británica Internacional de Grabado (Cartwright Hall, Bradford City Art Gallery and Museum, Inglaterra, 1972)

- XXIII Salón de Artistas Nacionales (Museo Nacional, Bogotá, 1972)

- Primer Salón Nacional de Artes Plásticas (Universidad Jorge Tadeo Lozano, Bogotá, 1972)

- II Bienal Americana de Artes Gráficas (Museo La Tertulia, Cali, 1973)

- IV Bienal Británica de Grabado (Bradford, Inglaterra, 1974)

- Grabados y Dibujos (Centro para Estudios Avanzados de las Artes Visuales, Instituto Tecnológico de Massachusetts, 1976)

- Asociación de Ingenieros (San Cristóbal, Venezuela, 1977)

- $\quad$ Sala Eugenio Mendoza (Caracas, 1978)

La participación de la artista en el ámbito artístico colombiano y latinoamericano puede rastrearse a lo largo de un quindenio, que va desde 1966 hasta 1981. Pero, al llegar a este año, y debido a su salida del país para radicarse en los Estados Unidos, desaparece cualquier indicio de su trabajo en los archivos consultados por el historiador Leonardo Caballero (2012) durante el proceso de elaboración de su monografía De concurso desierto a mención nacional: artistas plásticos santandereanos 1960-1980. Sin embargo, y con el material disponible, puede elaborarse una relación, en apariencia exhaustiva, para establecer la posición relativa de su 
trabajo en la cultura visual de un periodo caracterizado, entre tantas cosas, por la aparición de las primeras obras descritas con el rótulo de "arte conceptual" (Herrera 2011, 118-122), por la irrupción beligerante de propuestas gráficas militantes en los discursos de izquierda (Lucena 1975, 56-63 y 87-92), por las tendencias figurativas orientadas al hiperrealismo, el fotorrealismo y las temáticas urbanas y por la interpretación del legado de la geometría abstracta desde postulados minimalistas (Ponce de León 2004, 255).

Fue en este contexto que la producción con rasgos críticos de Porras, enfocada en explorar la cuestión de cómo entender visual y plásticamente la modernización colombiana, entró en contraste no solo con aquella perspectiva cultural propuesta por la estética de la resistencia de Marta Traba, ansiosa de asumir la diferencia del arte colombiano a partir de la idea de un tiempo circular que rechazara la ilusión de un desplazamiento histórico lineal y progresivo (Traba 2005, 158-159), sino con aquella perspectiva de izquierda, que justificaba la existencia del arte en los países subdesarrollados como un instrumento de lucha, agitación y propaganda en la revolución comunista (Lucena 1975, 64-69). Un carácter diferencial que se debe a que con sus obras gráficas Porras articuló una comprensión del arte caracterizada por su deseo de indagar desde la idea de progreso lo que en cierta tradición marxista ha sido designado como la "nueva naturaleza de las formas tecnológicas e industriales". Es decir, una naturaleza en la que el trabajo informado cultural e históricamente lograría traer de manera paulatina a la realidad un mundo donde por fin han sido alcanzadas la racionalidad y la libertad a través de la mediación productiva de los seres humanos (Buck-Morss 2004, 144-146).

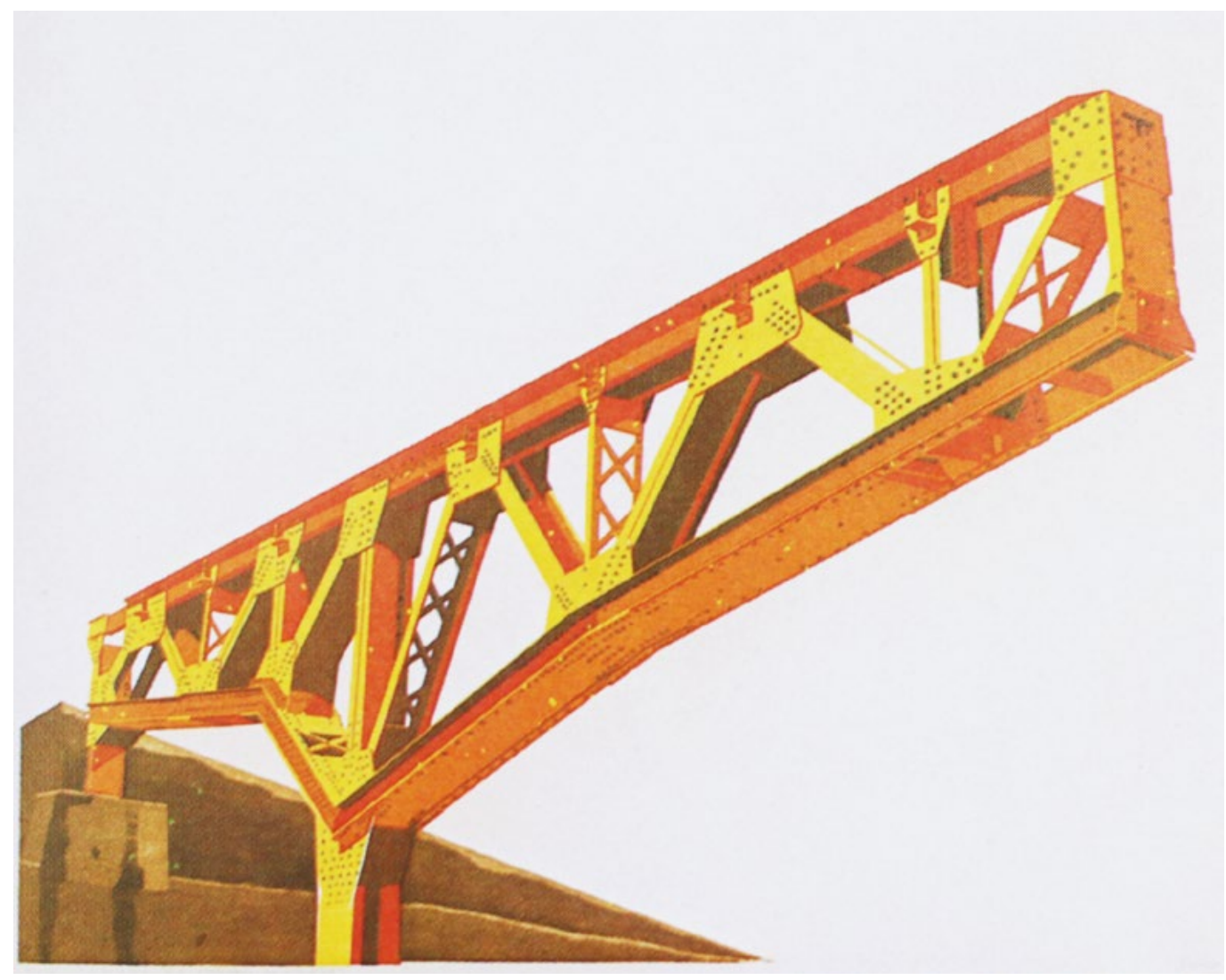

Figura 1. María Victoria Porras: Ramajes del hombre, su hierro I, 1971, litografía y aguatinta, $47 \times 57 \mathrm{~cm}$. 


\section{LOS RAMAJES DEL HOMBRE}

Probablemente la obra que mejor exprese esta interpretación sea el tríptico Ramajes del hombre, su hierro de 19711. Consistente en litografías coloreadas con aguatinta, estas piezas alcanzan su unidad formal mediante tres elementos claramente diferenciados en su articulación gráfica: 1) un fondo monocromático, 2) un soporte diagonal en las esquinas inferiores, ya sea a la izquierda del espectador en Ramajes del hombre, su hierro I y II, ya sea a la derecha en Ramajes del hombre, su hierro III, y 3) una estructura modular de carácter ingenieril y colores semisaturados, arraigada en dicho soporte, cuyas piezas se encuentran unidas con tornillos "a lo Negret" (figura 1).

Antes de arriesgar alguna interpretación iconográfica de estos elementos, hay que resaltar un aspecto peculiar de estas estructuras metálicas, el cual consiste en que se encuentran "tapiadas" en uno de sus extremos. ¿Cómo podría entenderse esto? ¿Acaso como una suspensión momentánea en su construcción o más bien como un índice sobre el fracaso definitivo de una modernidad clausurada? Sin entrar todavía a proponer una respuesta cuasifilosófica en clave constructivista de estas cuestiones, valdría la pena indagar como antesala sobre los tres fragmentos críticos que en su momento intentaron acercarse a la obra de la artista y que desde su sincronía histórica podrían arrojar algo de luz al respecto.

Elaborados por Germán Rubiano Caballero para su artículo "Panorama actual" (1977), incluido en la enciclopedia Historia del Arte Colombiano de la editorial Salvat, estos comentarios enmarcan las imágenes del tríptico a partir de la distinción tajante entre naturaleza y cultura, y su subsiguiente énfasis en la pureza de sus diseños estructurales. Así, el historiador señala que la producción de Porras se asemeja al "nuevo realismo" de Fernand Léger, dado que su obra se centra más en trabajar sobre "la realidad de la cultura que sobre la realidad de la naturaleza" (1674). Más adelante, en ese mismo párrafo, redondea tal idea con las siguientes palabras:

En verdad, el mundo que nos rodea en la vida diaria es en gran parte hecho por los hombres y no un mundo natural. [De modo que, frente] al oasis del campo [...], María Victoria Porras [ha] preferido la realidad industrial y urbana, que es hoy por hoy la realidad fundamental. (1675)

Por último, señala:

“En los [grabados de Porras], el tema fundamental es la estructura, la máquina, la conexión. En estos trabajos hay dos cosas importantes: diseño puro y clara referencia al espacio tridimensional" (1675).

El primer aspecto por cuestionar sería la pertinencia de parangonar las intenciones de la artista con las sostenidas en su momento por Léger. A este respecto, y para emplear las palabras de Peter Wollen, en su obra El asalto a la nevera: reflexiones sobre la cultura del siglo $X X:$ “ En el concepto de 'nuevo realismo' presentado por Fernand Léger, [...], se expresaba la nueva complejidad de la experiencia perceptiva que tipificaba a una sociedad de masas urbana y polifacética" $(2006,92)$. A este respecto, y sin negar la presencia de elementos de ingeniería arquitectónica propios de una sociedad urbana en las imágenes del mencionado tríptico, surge la cuestión de si estas estructuras no estarían mejor enmarcadas dentro de la tensión que hay entre un desiderátum modernizador y el factum perceptivo de una sociedad ya industrializada. Una duda que surge, porque, a pesar de que se acepte que los referentes 
de las imágenes remiten a la realidad inmediata de una sociedad industrializada, lo que se insinúa en los extremos clausurados de las estructuras representadas es que ha de irse más allá de la experiencia perceptiva para indagar sobre el sentido de la obra en el ámbito de la crítica del mundo empírico.

El segundo prejuicio que salta a la vista radica es el compromiso de Rubiano Caballero con una oposición estructural empleada para abrir subrepticiamente la distancia ontológica entre "la naturaleza" y "la ciudad". Una dicotomía que, más que esclarecer el significado de los significantes visuales y lingüísticos utilizados por la artista, deja en evidencia los rezagos de una concepción no materialista del mundo en el marco interpretativo del historiador. Concepción que, al señalar que la "realidad industrial y urbana" es "la realidad fundamental hoy por hoy", estaría clausurando de entrada cualquier posibilidad de pensar dialécticamente una doble síntesis que humanice la naturaleza y naturalice lo humano, tal como lo indica la expresión metafórica "ramajes del hombre" en el título de la obra (figura 2).

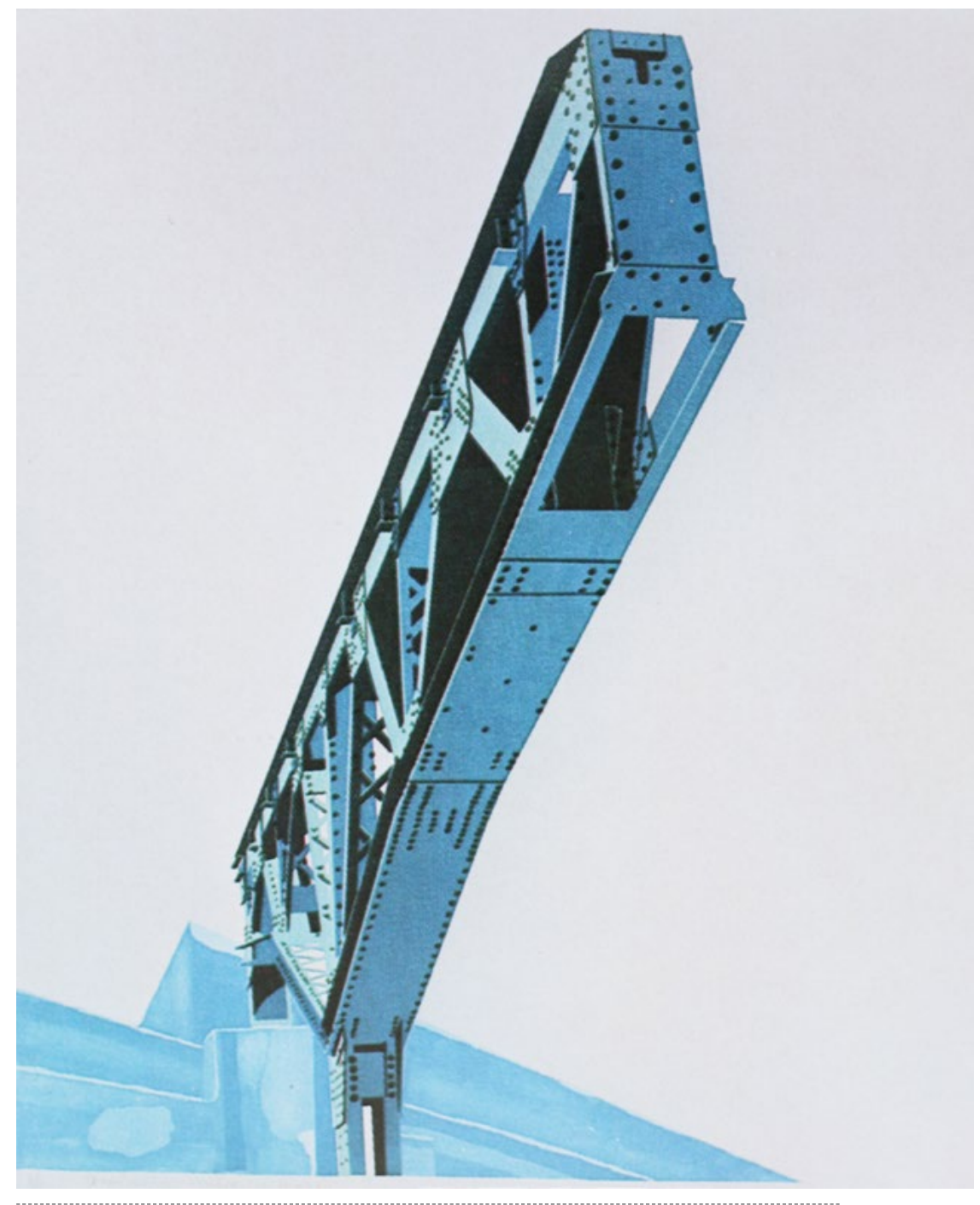

Figura 2. María Victoria Porras: Ramajes del hombre, su hierro II, 1971 , litografía y aguatinta, $57 \times 47 \mathrm{~cm}$. 
La sospecha que se tiene es que en este sesgo interpretativo se ha pasado por alto el hecho de que María Victoria Porras nació y creció en el epicentro petrolero por excelencia de Santander: Barrancabermeja, el cual, desde principios del siglo XX, ha representado para esta región el anhelo de resolver la tensión de un país a medio camino entre la extracción de las materias primas y la aspiración de conquistar el valor agregado de una economía secundaria mediante la aplicación de tecnología de punta. A este respecto, y en palabras de la artista:

El haber nacido y vivido en Barrancabermeja influenció profundamente el trabajo que realicé, sobre todo por la incidencia que tuvo la industrialización y la gran maquinaria industrial de la refinería en la elaboración de mis imágenes. En estas se fue representando, con bastantes modificaciones, valga decirlo, aquel sentido de dominancia de lo duro, frío y mecánico que me rodeaba. Un mundo que en mi imaginación contrastaba con el orgánico e incontrolable de aquella naturaleza selvática y el río que me rodeaba, pero que poco a poco fue convirtiéndose en algo más dentro del paisaje, como si de extensiones naturales se trataran. (entrevista con María Victoria Porras, febrero y mayo 2016)

A partir de esta declaración de la artista, más las dudas antes planteadas, podría decirse que no hay ningún problema en afirmar con Rubiano: " [María Victoria Porras] ha realizado una obra ambiciosa y experimental en la cual ha rendido permanente tributo a la máquina y a la tecnología" (1983, 163). Sin embargo, lo que está en duda es que Porras haya partido de un realismo como el de Léger, interesado en una sociedad que ya ha alcanzado un alto grado de modernización. Sobre todo porque el realismo en construcción de Porras, al menos tal y como se presenta en el mencionado tríptico, implica una indagación crítica sobre la relación entre la naturaleza (los ramajes), el hombre (su) y la tecnología (hierro), arraigada en su interés por saber en qué medida en Colombia la naturaleza tecnológica e inorgánica ha servido de suplemento a los seres humanos en su intento de resolver cuestiones prácticas surgidas en el curso de su historia.

\section{EN CLAVE CONSTRUCTIVISTA}

Ante la media luz arrojada por los fragmentos de Rubiano, a continuación se optará por reivindicar otras coordenadas de interpretación que sitúen el tríptico en el precario horizonte de interacción entre el hombre y la naturaleza a través de la tecnología. Unas coordenadas que, a diferencia de las esgrimidas por el historiador, han de permitir la articulación de marcadores, tales como "el fondo monocromático en Ramajes del hombre significa tal y tal cosa", que en su función referencial impidan soslayar el hecho de que la naturaleza nunca ha sido elidida de la obra, sino desplazada de forma oblicua hacia su título.

Por razones metodológicas, la interpretación que a continuación se propone no parte de los textos propios de la escritura sobre el arte colombiano, sino de fragmentos teóricos que, a pesar de su distancia geográfica, dado que los dos autores convocados son estadounidenses, facilitan esclarecer la relación de los significantes implicados en dicho tríptico. Para decirlo de forma sucinta: una interpretación que hace uso de las nociones de extensión prostética de Foster (2008) y de significación simbólica de Buck-Morss (2004), y en la que se presupone que las imágenes de los Ramajes del hombre, su hierro se articulan como signos dispuestos a la interpretación inmanente, dado que guardan gran parte de su sentido en su modo de expresión, no impide que más adelante, en otro movimiento, se bosqueje un horizonte mínimo sobre el ámbito cultural en el que surgió la obra, signado por el indicio de que se trató de un contexto determinado por la lucha heredada de las fracturas históricas abiertas en el mundo de las décadas de 1960 y 1970. 
La expresión extensiones prostéticas, tal como ha sido empleada por Foster, se refiere a un conjunto de suplementos inorgánicos que en el futurismo mecanizan el cuerpo humano con fines bélicos $(2008,127)$ y en el vorticismo lo blindan herméticamente para protegerlo en su integridad, no solo de la violencia tecnológica, sino de las fuerzas que tienden a disgregar su subjetividad (152). Algo que, en términos generales, implica el reconocimiento de carencias estructurales en el cuerpo orgánico y el intento de compensarlas de manera inorgánica. A este respecto, y a diferencia de Foster, podría señalarse que las extensiones prostéticas fueron pensadas en el ámbito del constructivismo de otra manera, es decir, desde cierto optimismo histórico, que las concibió como un conjunto de herramientas orientadas a superar la alienación tecnológica mediante el trabajo humano. Una diferencia interpretativa que no es para nada banal, ya que permite afirmar el potencial utópico de unos suplementos diseñados para transformar el mundo mediante la aplicación responsable de la tecnología y no solo para incrementar el potencial bélico y defensivo de los cuerpos expandidos. Y que, en su carácter revolucionario, reivindicarían, allende a Foster, el anhelo constructivista de que los elementos inorgánicos podrían llegar a existir como camaradas de la actividad humana en su lucha por una sociedad comunista (Buck-Morss 2004, 140).

Sobre la expresión significación simbólica, articulada por Susan Buck-Morss a partir de sus lecturas sobre Walter Benjamin, se empleará para referirse a aquel tipo de representación que surge de la relación dialéctica y transitoria entre lo empírico y lo utópico, con un modo de interacción que anticipa efímeramente lo que podría llegar a ser una forma natural-humana

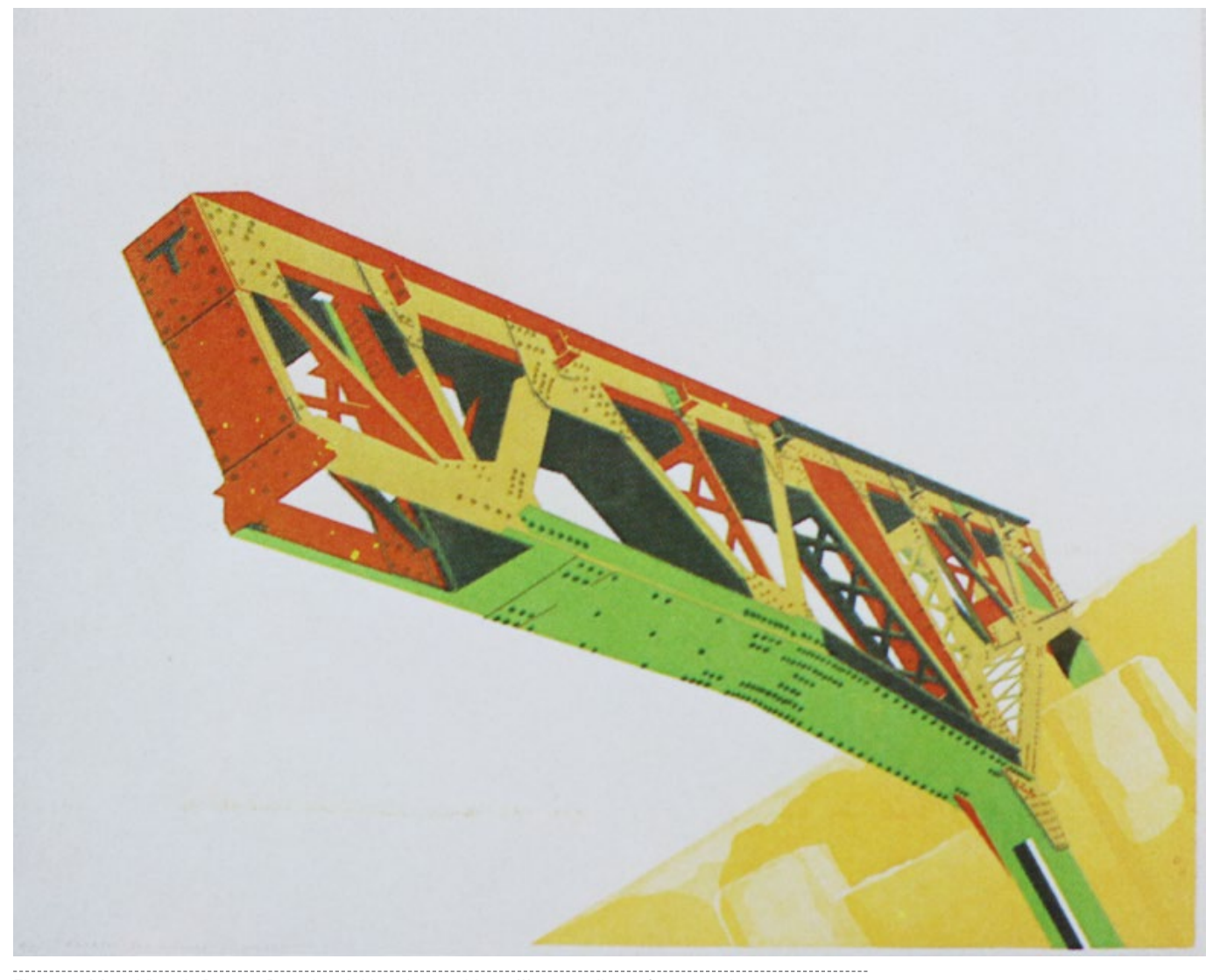

Figura 3. María Victoria Porras: Ramajes del hombre, su hierro III, 1971, litografía y aguatinta, $47 \times 57 \mathrm{~cm}$. 
objetivada a través del trabajo (Buck-Morss 1995, 189). Es decir, una forma cuya temporalidad se daría a modo de una iluminación profana, en cuyo fulgor se dejaría entrever lo que todavía no existe, pero que podría llegar a darse en el ámbito de lo real (134). Claro está, siempre y cuando exista el compromiso político de hacer un uso responsable del sorprendente progreso de la tecnología para "satisfacer las necesidades materiales y los deseos que constituyen en primer lugar el origen del sueño" (138) (figura 3).

A partir de estas precisiones conceptuales, se arriesgará la interpretación de que los significantes visuales y lingüísticos de Ramajes del hombre, su hierro pueden entenderse como extensiones prostéticas determinadas por un modo de significación simbólica. Se trataría de extensiones prostéticas en cuanto representan estructuras de la ingeniería civil que, a semejanza de las ramas de los árboles, se extienden hacia el cielo de la modernización, tratando de conquistar para la humanidad el espacio del progreso. Se dirá que son imágenes con significación simbólica, ya que articulan lo empírico de unas construcciones de tonos verdosos, amarillentos, sepias, azulados y anaranjados, con la sustracción monocromática del fondo, el intempestivo destello de luz blanca del todavía no de una modernidad postergada. En suma, se trataría de imágenes dialécticas que plantean el dilema de si todos los esfuerzos por modernizar a Colombia han terminado en ruinas, con el efecto práctico de desalentar las escasas pretensiones revolucionarias que aún puedan encontrarse en el presente o si su construcción tan solo se ha detenido momentáneamente para reactivarse más adelante, en la medida en que vuelvan a crecer las ramas del árbol-político.

\section{METALES PARA UNA SOLEDAD}

Hay algo enigmático en la obra gráfica de Porras, sobre todo si se sitúa en el contexto de las artes gráficas de la década de 1970 en Colombia, que consiste en que en sus imágenes el cuerpo humano se echa de menos, como si se tratara de un significante ausente. Una presencia que nunca se da visualmente en sus trabajos, pero que se desplaza hacia los títulos de las obras. Este es el caso de ... Y los hombres ausentes (1970), Metalurgia del silencio (1970), Sincrético, estructura sorda (1970), Epopeya ferrada en el tiempo (1970) y Metales para una soledad (1972). Títulos que hablan del hombre, sus acciones y su sustracción práctica desde la generalidad de un lenguaje que proyecta sobre las imágenes la cuestión de si el silencio, la sordera y la soledad pueden expresar de forma visual el adormecimiento de la voluntad (figura 4).

A este respecto, la obra Metales para una soledad (1972), hecha en acrílico y lápiz, representa una estructura metálica que flota en el vacío, como si se tratara de una forma platónica en estado puro, distante de materializarse en el espacio-tiempo de la realidad histórica. Un fragmento de negatividad crítica que, vale la pena señalarlo, se entronca con la forma en que entendieron las artes gráficas algunos de sus profesores de la Universidad Nacional de Colombia, donde la artista cursó la Carrera de Bellas Artes entre 1967-1971. Universidad que le dio acceso al ambiente cultural del Taller de Grabado, integrado entre profesores y estudiantes por Alfonso Quijano, Umberto Giangrandi, Rodolfo Velásquez, Alfonso Mateus, Augusto Rendón, Juan Manuel Salcedo, Darío Morales, Luis Paz, Franciso Rocca, Jorge Madriñán, entre otros (Valencia 1972). Y que, en gran parte, le permitió conocer algunos de los debates sobre la función que había de desempeñar el arte dentro de la nueva sociedad colombiana, tal y como lo manifiestan las siguientes palabras: 
Tengo que señalar que los tres profesores de la [Universidad Nacional de Colombia] que más influencia ejercieron en mi formación artística fueron Umberto Giangrandi, Carlos Granada y Luis Ángel Rengifo. Sobre Giangrandi tengo que decir que me impactó mucho la forma en que dejaba ver en su obra el dilema de la sociedad en los últimos años de los sesenta y los primeros de los setenta. Con su trabajo supo trasladar a un lenguaje gráfico cosas, como el descontento social, la crisis de la política y la angustia diaria de una sociedad que requería de los artistas para que dejaran constancia de su momento histórico. De Granada admiré el uso de su iconografía neofigurativa y expresionista para capturar la angustia de un país roto por la violencia. Finalmente, sobre Rengifo, que hacía parte junto a Giangrandi del Taller de Grabado, me gustaría decir que me enseñó la importancia de aprender aspectos técnicos relacionados con el grabado, especialmente la litografía, a la hora de emplearlos para dar testimonio de la realidad colombiana. (entrevista con María Victoria Porras, febrero y mayo de 2016)

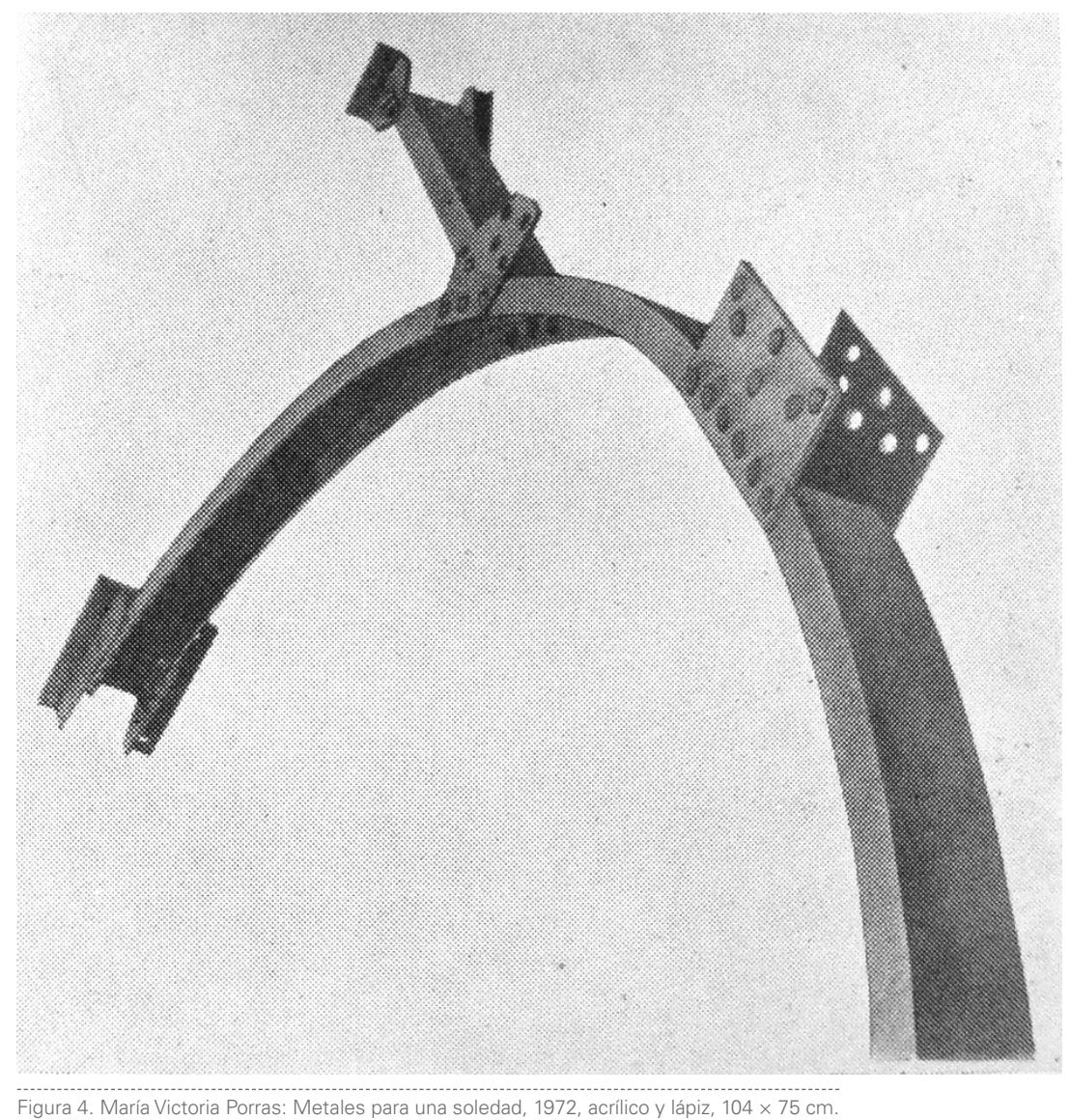

Lo que más llama la atención de estas palabras es que, además del reconocimiento de la influencia que sus profesores tuvieron en su comprensión del arte, resaltan la importancia de un arte comprometido existencialmente con dejar constancia de las luchas internas de una época. A este respecto, y dado su alejamiento de otras propuestas mucho más explícitas a la hora de dar testimonio de los acontecimientos históricos, habría que preguntarse por el modo en que sus obras pueden entenderse como signos del drama de una época. Para arriesgar una respuesta, podría decirse que no se tratan de representaciones icónicas, en cuyo reflejo conservarían las penas y glorias de un cuerpo politizado, sino más bien de fragmentos críticos que ven en la ausencia de ese mismo cuerpo el fracaso de la modernización colombiana. 
Tal vez por esta razón sus imágenes se alejaron de aquellas propuestas gráficas realizadas, entre otros, por Rodolfo Velásquez, Alfonso Quijano, Beatriz González, Umberto Giangrandi, Augusto Rendón, Clemencia Lucena, Pedro Alcántara Herrán, Taller 4 Rojo (Diego Arando y Nirma Zárate), Luis Paz y María de la Paz Jaramillo. Artistas que, sin soslayar las diferencias, establecieron secretos lazos entre los cuerpos representados en sus obras Homenaje a Camilo Torres (Velásquez 1966-1968), La cosecha de los violentos (Quijano 1968), Asesinada mujer en un hospedaje. No ha sido posible identificarla (González 1969), La liberación del hombre latinoamericano (Giangrandi 1970), Homenaje a cadete de la paz (Rendón 1971), Fuera el imperialismo yanqui (Lucena 1971), Retrato de un guerrero, 7 (Alcántara Herrán 1972), Colombia 72 (Taller 4 Rojo 1972), Yo soy el rey y amo la ley (Paz 1973) y Lady Macbeth o la señora Mac Bed (De la Paz Jaramillo 1973). Obras que giran alrededor de una presencia que, por más esquemática que hubiera sido, nunca dejó de ejercer su atracción gravitatoria hacia sistemas compositivos orientados a "la preservación encarnizada de la imagen del hombre" (Traba 2005, 161).

Así es como, la singularidad de la obra gráfica de Porras para el arte colombiano de la década de 1970 radica en que habla desde una posición crítica, casi filosófica, de estructuras abstraídas de sus usos ingenieriles prácticos, que no han logrado salir de la idealidad del dibujo y que en el papel corren el riesgo de convertirse en fósiles aislados, fragmentados y alegóricos de la modernización en Colombia. Una obra que habla de la tensión de creer en un movimiento histórico continuo e ininterrumpido, aun cuando, en el ámbito de los hechos, se evidencia como algo lento, muy lento, a una velocidad cercana a cero, hasta llegar al extremo de acumular polvo a su alrededor ${ }^{2}$. Pero, sobre todo, habla de un proyecto tecnológico y político que se vio clausurado, sin saberse si momentánea o definitivamente, porque los hombres han estado ausentes.

\section{EN CONSTRUCCIÓN}

Para finalizar este texto, se hubiera deseado rastrear con mayor profundidad el origen de la tendencia crítica en la obra de Porras, pero la tarea tuvo que postergarse a falta de suficientes fuentes directas e indirectas que evitasen caer en derivas interpretativas. Sin embargo, la sospecha que se tiene es que dicha tendencia probablemente ya existiera antes de que comenzara a estudiar en la Universidad Nacional. De tal modo que la hipótesis interpretativa consistiría en que fue el movimiento histórico de su natal Barrancabermeja el que la llevó a indagar sobre la relación entre la naturaleza y la tecnología en un horizonte marcado por las promesas del desarrollismo. Una suposición que podría arrojar luz no solo sobre el resto de su obra gráfica, sino sobre el modo en que sus obras escultóricas de la década de 1980, tales como Evolución (1980), Rostro (1980) y Ciudad de Carlos (1980), se orientaron hacia una reflexión en la que, a pesar de los errores, no todos los esfuerzos por alcanzar la modernización terminaron en el fracaso.

Sobre Barrancabermeja puede decirse sucintamente que es una población a orillas del río Magdalena, constituida originalmente como un campamento para la exploración de hidrocarburos en 1916, y que en sus comienzos estuvo marcada por la presencia de la empresa estadounidense Tropical Oil Company: La Troco o La T. O. C. (Aprile-Gniset 1997, 109). Una concesión al capital extranjero que, para bien o para mal, fue modificando el paisaje rural del puerto hasta convertirlo en un lugar dominado por elementos industriales y urbanísticos, y que fue trazando una historia de progreso y barbarie, cuyo desenlace llegó en 1948, año en el que fue revertida su situación jurídica por medio de la Ley 165 del 27 de diciembre. 
Fue por medio de esta disposición legal que se constituyó la Empresa Colombiana de Petróleos S. A. (Ecopetrol), cuyo fin era recuperar los campos de extracción y las instalaciones de la refinería de la Troco para la mayor gloria del país. Sin embargo, con su creación, también se desplegó un nuevo escenario, esta vez estatal, para otras tantas epopeyas caracterizadas, no solo por la riqueza material, sino por la conjunción de explotación y violencia que aún hoy en día siguen determinando el horizonte existencial de este puerto (Van Isschot 2015, XI-XVI).

Y es que, más que un lugar, Barrancabermeja también sería una travesía en el tiempo, que no solo habla de las luchas sociales, laborales y culturales de los trabajadores del petróleo, consideradas en su momento como grandes triunfos de la dignidad humana, sino de los sucesos que han dado forma a la tragedia de este municipio petrolero. Una narración acerca del énfasis modernizador de Ecopetrol y su compromiso con un proyecto caracterizado por el empleo pragmático del conocimiento para dar el salto desde una sociedad preindustrial hacia otra signada por una economía de productos con mayor valor agregado. Una historia cuyo telos, aún en construcción, y con todos sus espacios en blanco, dejaría entrever la posibilidad de entender de qué modo los intereses iconográficos anteriores a la formación artística de Porras en Bogotá estuvieron vinculados a las contingencias de la "hoguera encallada" (Cote 2003, 13), expresión acuñada por la poeta Andrea Cote para referirse al sofocante calor de este puerto calcinado.

\section{NOTAS}

1 Para quienes tengan intereses curatoriales o de cualquier otro orden académico alrededor de este tríptico, vale la pena señalar que la carpeta con estos trabajos hace parte de la Colección Permanente de Artes Plásticas de la Biblioteca Luis Ángel Arango del Banco de la República. Así, la pieza Ramajes del hombre, su hierro I tiene el número topográfico CP0318, la II tiene el CP0318 y la III el CP0320.

2 Para un estudio filosófico de la crítica a la historia como progreso, remítase a la lectura que hace Buck-Morss sobre la obra de Benjamin en su Dialéctica de la mirada, en el capítulo cuarto, titulado "Historia mítica: el fetiche." Para la idea de que la "historia acumula polvo," véase en ese mismo capítulo la página 112.

\section{REFERENCIAS}

Aprile-Gniset, Jacques. 1997. Génesis de Barrancabermeja. Barrancabermeja: Instituto Universitario de la Paz.

Buck-Morss, Susan. 1995. Dialéctica de la mirada: Walter Benjamin y el proyecto de los Pasajes. Madrid: Ediciones Visor.

- 2004. Mundo soñado y catástrofe: la desaparición de la utopía de masas en el Este y el Oeste. Madrid: Ediciones Visor.

Caballero Piza, Leonardo. 2012. “De concurso desierto a mención nacional: artistas santandereanos 1960-1980". Tesis de pregrado, Universidad Industrial de Santander.

Cote, Andrea. 2003. Puerto calcinado. Bogotá: Universidad Externado de Colombia.

Foster, Hal. 2008. Dioses prostéticos. Madrid: Akal. 
Herrera, María Mercedes. 2011. Emergencia del arte conceptual en Colombia (1968-1982). Bogotá: Pontificia Universidad Javeriana.

Instituto Colombiano de Cultura. 1972. XXIII Salón de Artistas Nacionales. Bogotá: Instituto Colombiano de Cultura.

Isschot, Luis van. 2015. The Social Origins of Human Rights: Protesting Political Violence in Colombia's Oil Capital, 1919-2010. Madison: The University of Wisconsin Press.

Lucena, Clemencia. 1975. Anotaciones políticas sobre la pintura colombiana. Bogotá: Bandera Roja.

Museo Nacional de Colombia. 1975. Primer Salón de Artes Plástica de Acopex. Bogotá: Museo Nacional de Colombia.

Ponce de León, Carolina. 2004. El efecto mariposa: ensayos sobre arte en Colombia 1985-2000. Bogotá: Alcaldía Mayor de Bogotá, Instituto Distrital de Cultura y Turismo.

Porras, María Victoria. 1975. "Metales para una soledad". En Primer Salón de Artes Plásticas de Acopex. Bogotá: Museo Nacional de Colombia.

— 1977. "Ramajes del hombre I, II y III." Historia del Arte Colombiano 7: 1671.

Rubiano Caballero, Germán. 1977. "Panorama actual." Historia del Arte Colombiano 7: 1661-1680.

- 1983. Escultura colombiana del siglo XX. Bogotá: Fondo Cultural Cafetero.

Traba, Marta. 2005. Dos décadas vulnerables en las artes plásticas latinoamericanas, 1950-1970. Buenos Aires: Siglo XXI.

Valencia Diago, Gloria. 1972. “De grabado, no de fotografía, el premio de Alfonso Quijano". El Tiempo, 1 de septiembre.

Wollen, Peter. 2006. El asalto a la nevera: reflexiones sobre la cultura del siglo XX. Traducido por Cristina Pila Aldao. Madrid: Akal.

\section{Cómo citar este artículo:}

Camargo Flórez, Martín Alonso \& Caballero Piza, Andrés Leonardo. 2017. "María Victoria Porras en clave constructivista" Cuadernos de Música, Artes Visuales y Artes Escénicas 12 (1): 159-171. doi:10.11144/Javeriana.mavae12-1.mvpc. 